\title{
Is Food Price Inflation Transitory? Empirical Evidence from Sri Lanka
}

\author{
Selliah Sivarajasingham ${ }^{1} \&$ Shri-Dewi Applanaidu ${ }^{1}$ \\ ${ }^{1}$ School of Economics, Finance and Banking, College of Business, Universiti Utara Malaysia, Sintok, Kedah, \\ Malaysia \\ Correspondence: Selliah Sivarajasingham, School of Economics, Finance and Banking, College of Business, \\ Universiti Utara Malaysia, 06010 Sintok, Kedah, Malaysia. Tel: 60-111-885-4132. E-mail: ssivaraj@pdn.ac.lk; \\ dewi@uum.edu.my
}

\author{
Received: October 18, 2014 Accepted: February 13, 2015 Online Published: May 15, 2015 \\ doi:10.5539/ass.v11n15p22 URL: http://dx.doi.org/10.5539/ass.v11n15p22
}

\begin{abstract}
Food prices are excluded from core measures of inflation in many countries assuming food prices are transitory. Exclusion of food prices may lead to information loss, leading to higher inflationary expectations, a downward bias to forecasts of future inflation and lags in policy responses. Assumption that log food price series behave by way of $\mathrm{I}(1)$ and differenced $\log$ food price series linger in the manner of $\mathrm{I}(0)$ process leads to model misspecification. Correct identification of the memory in the food price series is vital for the correct model specification and is important for policy makers. This study aims to examine whether food price inflation is transitory in Sri Lanka by estimating the memory properties of food price series using non-parametric, semi-parametric and parametric tests. The study covers the period from January, 2003 to December, 2013. Results show that food price inflation, nonfood price inflation and headline inflation, and global food price inflation series are fractionally integrated. Food price series in Sri Lanka commoves with global food prices. Research findings show that food price inflation is not transitory, long memory series. The outcomes of this attempt have consequential implications towards food policy, trade policy and monetary policy makers. These findings suggest that neglecting food prices may render the core inflation measure a biased measure of long run inflation.
\end{abstract}

Keywords: fractionally integration, food price inflation, long memory, Sri Lanka, transitory

\section{Introduction}

In today's globalized world, food price dynamics have a noticeable influence on the world's economic and political stableness as well as on the wellbeing of every single country. High and increasing food prices pose a significant policy challenge to macroeconomic stability in developing countries where the food expenditure share in household expenditure is relatively high (Mishra \& Roy, 2012). Extreme volatility and increasing trend of food prices has energized the necessity of perceiving the behavior and the characteristics of food prices. According to Deaton (1999), a better understanding of commodity prices is necessary to construct good policy.

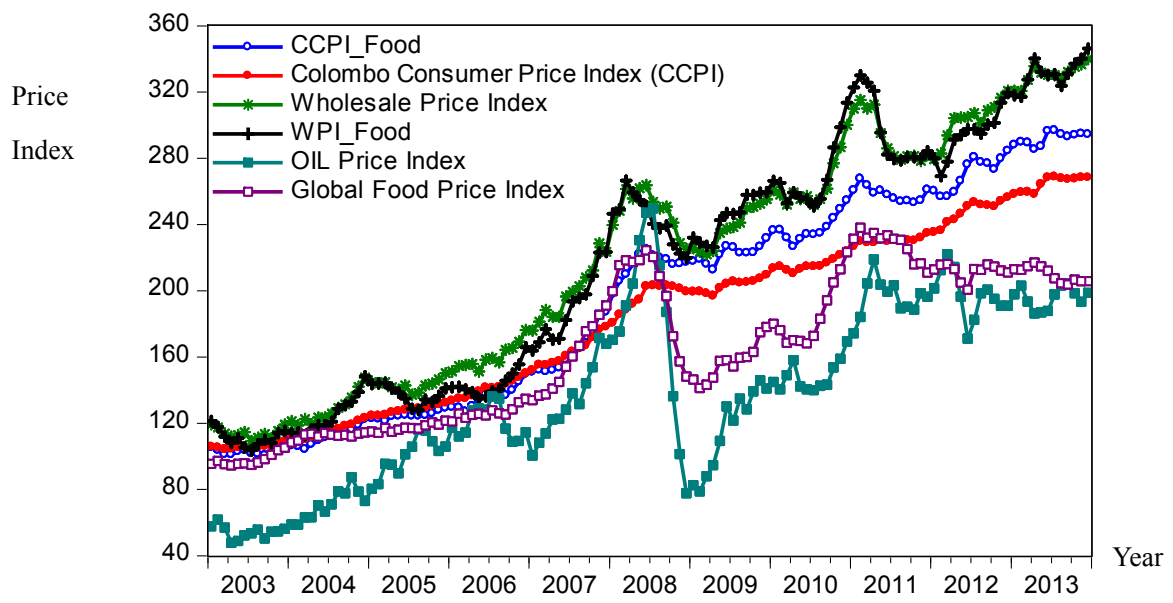

Figure 1. Domestic and global food price dynamics: Sri Lanka 2003-2013 
Figure 1 exhibits the mean and variance of global and domestic food prices have been increasing. Relatively oil price has more volatility which determine food price. Global food price volatility appears to have increased in recent years.

Food expenditure accounts to about one third of total expenditure in the world. However, countries in South Asia expend more than 50 percent on food and those in West Europe and North America the least (16\%) (Wu, 2004). Sri Lanka is a small an import dependent and open economy. It is a net food importer. Food and beverages components in Colombo Consumer Price Index (CCPI) consists mainly rice, sugar, wheat, dairy products, lentils. According to Household Income and Expenditure Survey (HIES) in 2012, 80 percent of households spend more than 41 percent of their income on food and 50 percent of households spend more than 50 percent of their income on food and drink in Sri Lanka.

The food expenditure ratio is one of the primary indicators used to gauge the living standards of a population. The proportion of expenditure on food and drink to total expenditure is called the food expenditure ratio and it is generally given as a percentage. According to the HIES-2012/13, household population in Sri Lanka was 20.2 million. The urban population consists 3.6 million while rural population 15.7 million and estate population 0.9 million. These statistics show that majority of the Sri Lankan's population lives in rural area. The composition of population who live in rural and estate area is more than 80 percent from the total population in Sri Lanka. Table 1 shows the food ratio in Sri Lanka according to area of population.

Table 1. The proportion of food expenditure to total expenditure (in percentage) 2012/13

\begin{tabular}{ccc}
\hline Sectors & $2009 / 10$ & 2012 \\
\hline ALL & 42 & 37.6 \\
Urban & 36 & 31.4 \\
Rural & 44 & 39.1 \\
Estate & 51 & 49.6 \\
\hline
\end{tabular}

Source: HIES-2009/10, 2012/13

The food ratio distribution among area of population in 2012/13 shows that those who live in rural and estate area have higher food ratio compared to those in urban. Cereals (rice, wheat flour etc.), and prepared food (bread, buns, hoppers etc.) are known as the two major branches, on which the foremost proportions of the total expenditure on food are expended. The urban sector expend mostly on prepared food over the cereals whilst the estate sector expends slightly on prepared food (Table 2).

Table 2. Average monthly household expenditure (\%) by major food category and sector in Sri Lanka-2012

\begin{tabular}{ccccc}
\hline Major Food Category & Sri Lanka & Urban & Rural & Estate \\
\hline Cereals & 16.3 & 12.1 & 16.9 & 27.4 \\
Prepared foods & 11.8 & 17.4 & 10.6 & 5.9 \\
Pulses & 3.4 & 2.7 & 3.5 & 5 \\
Vegetables & 7.9 & 6.8 & 8.2 & 8 \\
Meat & 4.4 & 6 & 4 & 4.2 \\
Fish & 9.2 & 11.2 & 9 & 3.9 \\
Dried Fish & 4 & 2.9 & 4.3 & 2.6 \\
Coconuts & 5.2 & 4.4 & 5.4 & 4.9 \\
Condiments & 8.8 & 7.5 & 9.1 & 9.2 \\
Milk \&Milk foods & 9.4 & 10.6 & 9 & 9.8 \\
Fats and Oil & 2.3 & 1.7 & 2.4 & 3.2 \\
Sugar , Juggery, Treacle & 3.1 & 2.6 & 3.2 & 3.2 \\
Fruits & 3.3 & 3.6 & 3.3 & 1.9 \\
Other food items & 10.7 & 10.4 & 10.8 & 10.8 \\
All & 100 & 100 & 100 & 100 \\
\hline
\end{tabular}

Source: HIES-2012/13, Sri Lanka

Table 3 shows the contribution of food and non-alcoholic beverages to annual average inflation in Sri Lanka from 2009 to 2013. The contribution has increased continuously except 2012. 
Table 3. Contribution of food and non- alcoholic beverages to annual average inflation

\begin{tabular}{lc}
\hline Year & Contribution (\%) \\
\hline 2009 & 41.3 \\
2010 & 50.8 \\
2011 & 59.9 \\
2012 & 29.3 \\
2013 & 52 \\
\hline
\end{tabular}

Source: Department of Census and Statistics, Central Bank of Sri Lanka-2013

Being an open and dependent economy, Sri Lanka is highly vulnerable to shocks in the international food prices since the food consumption basket has a large food imported component. The share of food and beverages imports expenditure of total consumer goods imports expenditure is around 50 percent for the period of 2009-2012 (Central Bank of Sri Lanka, 2013). This indicates that food items plays important role even in total import expenditure in Sri Lanka. The main food items of imports are sugar, milk and milk products, red-dhal, wheat and maize, big onions, potato and Maldives fish. Food and beverages and wheat and maize accounts approximately in the range of 9-12 percent of total imports expenditure.

Given the structure of the Sri Lankan economy, food prices have a significant inter linkages between global food prices and headline underlying inflation. Food price inflation is a serious issue faced by many countries including Sri Lanka. In many countries, food inflation is higher than headline inflation. One can see that food prices have become increasingly stable recently. In Europe and Central Asia, overall inflation averaged 10 percentage whereas food inflation was at 15 percentage in 2007 (Bhatt \& Kishor, 2011).

Accurate measurement of inflation is essential for the policy makers in order to effectively monitor prices in the economy. Two measures of inflation are typically identified in any macroeconomics text books, namely the headline inflation and core inflation. The headline inflation in most countries is measured as a percentage change in the Consumer Price Index (CPI). The core inflation is computed by removing food and energy prices from CPI. In the recent years, rising global food prices and energy prices are contributing to high inflation in an economy (Al-Eyd, Amaglobeli, Shukurov, \& Sumlinski, 2012).

Food prices are generally discarded from measures of inflation assuming food prices are transitory in nature. Core inflation excludes food and energy prices. Core inflation measures are designed to solve the problem of transitory noise. But, the core inflation systematically under estimates headline inflation when food inflation is persistent. Exclusion of food prices may lead to loose valuable information about inflation and lead to inaccurate measurement of the underlying long run trend in inflation. Cecchetti, Hooper, Kasman, Schoenholtz and Watson, (2007) argued that ignoring food and energy prices particularly in recent times when they have consistently been rising faster than other prices, could lead to biased estimates of medium-term inflation. Core inflation that excludes food prices can misspecify general inflation, leads to higher inflationary expectations, a downward bias of future inflation and lags in policy responses.

In most advanced economies, food and energy is excluded in core inflation. The characteristics of food and non-food prices in emerging economies are not same as developed countries. Policy makers discount food price component from CPI stating the argument that food price shocks are not persistent in assessing the level of inflation. In line with the international practice adopted by many countries, the core inflation in Sri Lanka, first, is introduced in 2007 by removing food and energy items in CPI index. If shocks dissipate quickly, then their effect on headline inflation will not be significant beyond the short run. The shock is said to be transitory if the effect of the shock dies out over time and if the effect of a shock does not die out over time, the shock is said to be persistent (permanent). In the case of high persistence, food inflation spikes up from a shock will take longer to adjust downwards relative to the case of low persistence. Persistent food price shocks are much more likely to feed into inflationary expectations, (Walsh, 2011). Thus, the memory characteristics of food price series are necessary to be investigated.

Correct identification of the memory in the food price series is vital for the correct model specification and is important for policy analysts. It is practically impossible to determine whether food price dynamics are transitory or permanent in nature. The primary objective of this study is to investigate the long memory properties of the food price inflation series in Sri Lanka. The specific objectives are: (i) to estimate the fractional integration parameter and explore the persistence of food price dynamics in Sri Lanka and (ii) to estimate persistence of volatility of food price dynamics. 
The structure of the paper is as follows. Section 2 briefly reviews the literature. Section 3 describes data and methodology of the study. Section 4 discusses the empirical results obtained from various econometric techniques applied for food prices and the final section concludes, and gives some recommendations from the results obtained.

\section{Literature Review}

Several studies such as Klein (1976), Ball \& Cecchetti (1990), Barsky (1987) have examined the characteristics of aggregate inflation for developed countries namely Brazil, Canada, France, Germany, Israel, Italy, Japan, United kingdom (UK) and United States (U.S). They found empirical evidence of two unit roots in prices, so that any shock has a permanent impact on inflation. Virtually all contemporary studies speculate integer degrees of differentiation, testing stationarity/nonstationarity with unit root tests and cointegration techniques.

The fractional integration or $\mathrm{I}(d)$ models have been used extensively in the case of developed countries. For instance, Backus and Zin (1993) found a fractional degree of integration in the U.S. monthly data regarding inflation persistence. Hassler (1993) and Delgado and Robinson (1994) found strong evidence of long memory or $\mathrm{I}(d)$ behavior in the Swiss and Spanish inflation rates respectively. De Boef \& Granato (1997) reviewed that some data are long memory processes but do not have unit roots, especially in the range $0<d<1$. Even though it does not contain a unit root, it does have long memory, whereby shocks to the series persist for at least 12 months. Hassler \& Wolters (1995) have examined inflation rates of five developed countries for the period of 1969 to 1992 and found that inflation series are having long memory. They found that the order of integration of the series are significantly different from 1 (one) as well as 0 (zero). Hassler (1993), Baillie, Bollerslev \& Mikkelsen (1996) studied monthly post-World War II CPI inflation in ten countries and found evidence of long memory with mean-reverting demeanour in all the countries excluding Japan. In particularly the same evidence was found by Hassler \& Wolters (1995) and Baum, Barkoulas \& Caglayan, (1999). Bos, Franses \& Ooms, (1999) examined inflation in the G7 countries, found that the evidence of long memory.

A number of studies have examined the long memory hypothesis using data from agricultural commodity prices. Kohzadi \& Boyd (1995), Barkoulas, Labys \& Onochie (1997), Jin \& Frechette (2004), Kovacs, Huszsvai \& Balogh (2014) are few examples of them. Stigler \& Prakash (2011) have examined time series properties of commodity prices using 24 commodities for developed countries. There is a lack of evidence of $\mathrm{I}(d)$ behaviour for food inflation rates for developing countries (Kallon, 1994; Moriyama \& Naseer, 2009). Studies such as Gilbert (2010), Cooke (2009), Leoning, Durevall, \& Birru (2009), Walsh (2011), Sumlinski, Al-Eyd, Amaglobeli, \& Shukurov (2012) focused food price dynamics in African countries. Rangasamy (2009) found that food inflation is highly persistent in South Africa.

Many studies such as Diebold and Nerlove, (1989), Hsieh (1988), Baillie \& Myers (1991) investigate volatility patterns in various asset return data, including stock returns, exchange rates, but there are very few studies such as Von Braun \& Tadesse (2012), and Gilbert \& Morgan (2010), examine volatility of agricultural commodity and food prices. Vega \& Wynne (2003), Cecchetti (1997), Culter (2001), Bilke \& Stracca (2007) found that food prices are relatively persistent in Euro area. There is a large-scale project of the Eurosystem entitled Inflation Persistence Network (EIPN) implemented during the period of 2003-2005 to analyse inflation persistence for the euro area. There are common concern about the impacts of high food prices on poor people and social, political stability in all countries.

However, there are no studies investigating the memory properties of food price series in Asia, Sri Lanka in particular using fractional integration technique. So, this study intends to fill the gap in the literature. Further, this study will be a more comprehensive study about food price and food price volatility dynamics based on recent econometric time series analysis in Sri Lanka. A comprehensive understanding of time series and statistical properties of food prices in Sri Lanka might provide useful implications for the direction of future research and effective food and monetary, agricultural and trade policies. Therefore, this study would contribute significantly to the existing knowledge.

\section{Methods}

\subsection{Data and Variables}

Data used in this study are monthly data spanning from January 2003 to December 2013. The starting time period, 2003 was selected as food prices started to move upward exponentially in Sri Lanka. Variables used in this study include;

i) Colombo Consumer Price Indices for all items $\left(\mathrm{CCPI}_{\mathrm{t}}\right)$

ii) Colombo Consumer Price Indices for Food and non-alcoholic beverages, $\left(\mathrm{CCPI}_{\mathrm{f}, \mathrm{t}}\right)$ 
iii) Colombo Consumer Price Indices for non-food $\left(\mathrm{CCPI}_{\mathrm{nf}, \mathrm{t}}\right)$

iv) Whole Sale Price Index $\left(\mathrm{WPI}_{t}\right)$

v) Whole Sale Food Price Index $\left(\mathrm{WPI}_{\mathrm{f}, \mathrm{t}}\right)$

vi) Global Food Price Index $\left(\mathrm{GFPI}_{\mathrm{t}}\right)$.

Consumer price indices were collected from Department of Census and Statistics, Sri Lanka. Wholesale price indices were collected from Central Bank Annual report 2013. Global food price indices were collected from FAO website. All the series are transformed into natural logarithm and seasonally adjusted. Inflation is defined as log difference series. The Hodrick-Prescott (HP) filter is used in this study to separate the trend component and cycle component of a series. Inflation definition and variables are listed in the Table 4.

Table 4. Definition of variables used in the study

\begin{tabular}{|c|c|c|}
\hline Price Index & Log transformation & Inflation \\
\hline CCPI & $\mathrm{LCCPI}=\ln (\mathrm{CCPI})$ & $\pi_{\mathrm{t}, \mathrm{c}}=\left(\mathrm{LCCPI}-\mathrm{LCCPI}_{-1}\right) * 100$ \\
\hline $\mathrm{CCPI}_{\mathrm{f}}$ & LCCPIf=ln(CCPIf) & $\pi_{\mathrm{tf}}=\left(\mathrm{LCCP}_{\mathrm{f}, \mathrm{t}}-\mathrm{LCCP}_{\mathrm{f}, \mathrm{t}-1}\right) * 100$ \\
\hline $\mathrm{CCPI}_{\mathrm{nf}}$ & LCCPInf $=\ln ($ CCPInf $)$ & $\pi_{\mathrm{tnf}}=\left(\mathrm{LCCP}_{\mathrm{nff}, \mathrm{t}}-\mathrm{LCCP}_{\mathrm{nf}, t-1}\right) * 100$ \\
\hline WPI & LWPI=ln(WPI) & $\pi_{\mathrm{t}, \mathrm{wp}}=\left(\mathrm{LWPI}_{, \mathrm{t}}-\mathrm{LWPI}_{\mathrm{t}-1}\right) * 100$ \\
\hline $\mathrm{WPI}_{\mathrm{f}}$ & LWPIf=ln(WPIf) & $\pi_{t, \mathrm{wf}}=\left(\mathrm{LWPI}_{\mathrm{t}, \mathrm{t}}-\mathrm{LWPI}_{\mathrm{t}, \mathrm{t}-1}\right) * 100$ \\
\hline $\mathrm{GFPI}_{\mathrm{t}}$ & LGFPI $=\ln (\mathrm{GFPI})$ & $\pi_{t, \mathrm{Gf}}=\left(\mathrm{LGFPI}_{\mathrm{t}, \mathrm{t}}-\mathrm{LGFP}_{\mathrm{t}, \mathrm{t}-1}\right) * 100$ \\
\hline
\end{tabular}

Note: Food category consists of bread and cereals, meat, fish and sea food, milk, cheese and eggs, oil and fats, fruits, vegetables, sugar, jam, honey, chocolate and confectionary food products. Non-Alcoholic beverages consist of coffee, tea, cocoa, mineral water, soft drinks fruit and vegetable juice.

Nonfood group consist clothing and foot wear, housing, water, electricity, gas and other fuels, furnishing household equipment and routine household maintenance, health, transport, communication, recreation and culture, education and miscellaneous goods and services.

\subsection{Analytical Methods}

This study uses various econometric techniques to achieve the objectives of this study. Exploratory Data Analysis (EDA) and parametric, semi parametric and non-parametric approaches are used. Various time series econometrics tools are used to estimate memory properties of food price distribution. These techniques are based for first four "moments" of food price distribution: its mean, volatility, asymmetry, and kurtosis that describe the food price distributions. This paper investigates time series dynamics of these moments which are time dependent. Special emphasis is given to the time persistence of the first two moments, namely the hypothesis of mean-reversion and volatility clustering.

\subsubsection{Exploratory Data Analysis (EDA)}

First, EDA and non-parametric techniques (numerical descriptive statistics and graphical displays; line graphs, histograms, and autocorrelation function, correlograms, kernel density estimate, confidence ellipse,) are used to find novel and useful information that might otherwise remain unknown. These techniques may uncover the underlying structure of dynamic behaviour of the food price series. The purpose of using various techniques is in order to get robust results as each estimation techniques may have limitations.

\subsubsection{Unit Root Test}

To investigate the random walk nature (issue of unit roots) and long memory process in empirical food price behaviour in Sri Lanka, standard unit root tests; the Augmented Dickey- Fuller (ADF), the Phillips and Perron (PP) test and the Kwiatkowski-Phillips-Schmidt-Shin (KPSS) tests are implemented on all food price series. The ADF and PP tests are used to test the null hypothesis of the series are non-stationary (I(1), against the alternative hypothesis that they are stationary I(0). The KPSS test is implemented in another way: null hypothesis: series is stationary against series are non- stationary. These tests can only identify whether series are I(0) or I(1). These tests fail to separate a highly persistent stationary process from non-stationary process. A stationary process will not drift too far away from its mean value because of the finite variance. By contrast, a non-stationary time series, I(1), will have time varying mean or variance or both. They only identify the series are $\mathrm{I}(0)$ or $\mathrm{I}(1)$. So we use other recent developed model to estimate long memory parameter. 


\subsubsection{The Rescaled Range Statistic (Hurst Exponent): Nonparametric Approach}

Among various methods that measure long memory, the "rescaled range" is the most extensively used. Mandelbrot (1975) has suggested the $R / S$ statistic which was developed by Hurst (1951) in the study of river discharges. The "range over standard deviation statistic" or $(R / S)$ to detect long range dependence of a series has the form

$$
(R / S)_{n}=\frac{1}{s_{n}}\left[\operatorname{Max} \sum_{j=1}^{k}\left(x_{j}-\bar{x}_{n}\right)-\operatorname{Min} \sum_{j=1}^{k}\left(x_{j}-\bar{x}_{n}\right)\right]
$$

$$
\text { Where } 1 \leq \mathrm{k} \leq \mathrm{n}
$$

$R(n)$ is the range of the first $\mathrm{n}$ values, and $S(n)$ is their standard deviation. The $R / S$ statistic is the range of partial sums of deviations of a time series from its mean, rescaled by its standard deviation. The Hurst exponent, $H$, is defined in terms of the asymptotic behaviour of the rescaled range as a function of the time span of a time series as follows:

$$
E[R(n) / S(n)]=C n^{H} \text { as } \mathrm{n} \rightarrow \infty
$$

Where $\mathrm{R}(\mathrm{n})$ is the range of the first $\mathrm{n}$ values, and $\mathrm{S}(\mathrm{n})$ is their standard deviation, $E($.$) is the expected value, \mathrm{n}$ is the time span of the observation (number of data points in a time series) and $\mathrm{C}$ is a constant. The Hurst exponent is estimated by fitting the power law to the data. The rate of decay is estimated by the R/S method (Beran, 1994). If $0.5<\mathrm{H}<1$, the series indicates persistent behavior/long memory. If $0.0<H<0.5$, then the series is called anti-persistent.

\subsubsection{Geweke and Porter Hudak (GPH ) Estimate-Semi-Parametric Approach}

Semi parametric approaches avoid the misspecification issue emerging in fully specific parsimonious parametric models and permit to explore the $\mathrm{I}(d)$ structure of the series constraining the long run behavior to be an $\mathrm{I}(0)$ process. Geweke \& Porter Hudak, (1983) propose a log periodogram estimate of fractional " $d$ " having the form

$$
\log \left(I\left(\lambda_{j}\right)\right)=\text { const }+d \log \left(\left\{2 \sin \left(\lambda_{j} / 2\right)\right\}^{-2}\right)+\text { error }
$$

with

$$
\hat{d}=\sum_{s=1}^{\mathrm{m}} \mathrm{y}_{\mathrm{s}} \log I\left(\lambda_{s}\right) /\left(2 \sum_{\mathrm{s}=1}^{\mathrm{m}} \mathrm{y}_{\mathrm{s}}^{2}\right)
$$

\subsubsection{Long Memory and ARFIMA Model}

It is widely believed that the logs of macroeconomic time series variables are containing a unit root (Granger \& Joyeux, 1980; Hosking, 1981). However, some series evidently do not possess a unit root, while they show signs of dependence and possess long memory (Wang \& Tomek, 2007). The most commonly used $\operatorname{ARMA}(p, q)$ model is not well suited to model the long run behaviour of time series. ARIMA model examine the temporal dynamics of an economic variable as integer integration under which time series are presumed to be integrated order zero or one. This is highly restrictive, restricted to the integer domain. $\operatorname{ARFIMA}(p, d, q)$ model is introduced to describe fractional integrated variables.

A time series, $\mathrm{y}=\left\{\mathrm{y}_{1}, \mathrm{y}_{2}, \ldots \mathrm{y}_{\mathrm{T}}\right\}$, follows an $\operatorname{ARFIMA}(p, d, q)$ process if

$$
\Phi(L)(1-L)^{d} y_{t}=\Theta(L) \varepsilon_{t}
$$

where $\varepsilon_{\mathrm{t}} \sim \operatorname{iid}\left(0, \sigma^{2}\right), \quad \mathrm{L} \quad$ is the backward-shift operator, $\Phi(B)=1-\phi_{1} B-\ldots . .-\phi_{p} B^{p}$, $\Theta(B)=1+\theta_{1} B+\ldots \ldots . .+\theta_{q} B^{q}$, and $(1-B)^{d}$ is the fractional differencing operator defined by

$$
(1-L)^{d}=\sum_{k=0}^{\infty} \Gamma(\mathrm{k}-\mathrm{d}) \mathrm{L}^{\mathrm{k}} / \Gamma(\mathrm{k}+1) \Gamma(-\mathrm{d})
$$

$\Gamma($.$) is the gamma function, \mathrm{y}_{\mathrm{t}}$ is both stationary and invertible if the roots $\Phi(L)$ and $\Theta(L)$ are outside the unit circle and $d<|0.5|$. The parameter $d$ is allowed to assume any real value. Long-memory processes are stationary processes whose autocorrelation functions decay more slowly than short-memory processes. Hosking (1981) showed that the autocorrelation, $\rho\left(\right.$.), of an ARFIMA processes is proportional of $k^{2 d-1}$ as $k \rightarrow \infty$, 
[ $\rho(k) \propto k^{2 d-1}$ ]. It implies that the autocorrelations of the ARFIMA processes decay hyperbolically to zero as $k \rightarrow \infty \operatorname{ARFIMA}(p, d, q)$ processes are known to be capable of modeling long run persistence.

When $d=0$, the series is stationary and showing short memory and mean reversion with finite variance. In this case, the effects of a shock in a variable are transitory, If $0<d<0.5$, the series behave like fractionally integrated indicating strong dependence between past observations, long memory, mean reversion, and covariance stationary. The effects of a shock in real output lasts in the long run decaying at a slower, hyperbolic rate. When $0<d<1$ the series is no more covariance stationary but mean reverting. Effect of a shock in the series is long lasting and decays at an even slower rate. When $d=1$, series is integrated order one, having unit root, nonstationary, with infinite memory, and non-mean reverting. In this case, effect of a shock in the series is permanent, having a long run effect, forever persistent. If $d>1$, the series is non-stationary, non-mean reverting with infinite memory. In this case, effect of a shock is diverging forever. For $d<1$, the series is mean-reverting, stationary. For $-0.5<d<0$ the series is stationary, intermediate memory (Antipersistent). The process is non-stationary for $d \geq 0.5$, 'because it possesses infinite variance (Granger \& Joyeux, 1980), however, long range dependence is associated all non zero, $d>0$. Thus, the memory property of a process depends on significantly on the value of $d$. ARFIMA model can be used to estimate the parameter $d$ which describes long run memory of the series and if the parameter $d$ is significant it gives evidence of long memory. Using the theoretical knowledge given above, we test food price series whether has it long memory.

\section{Results}

\subsection{Basic Features of Food Price Dynamics in Sri Lanka}

The basic features of these price series are examined by visual inspection using various graphs. Visual inspection indicates that the series includes non-periodical cycles. They are non-stationary. The average food price change during the sample period is higher than that of the non-food price changes. Food inflation average exceeds the headline inflation average. Food inflation is having high volatility than nonfood inflation, headline inflation, $\left(\mathrm{SD}_{\text {finf }}=1.7, \mathrm{SD}_{\text {nonfinf }}=1.04, \mathrm{SD}_{\text {inf }}=0.84\right)$. Mean and variance of the food inflation distribution change over time. Variability of food inflation series vary over time and appears in clusters. There is a positive strong correlation, $r=0.78(0.00)$, between movements in head line and food inflation. Figure 1 exhibits a time series plot of monthly food price, nonfood price, overall CPI and world oil price, and global food price indices. All price series are moving upward with volatile.

Two characteristics are emerged from the Figure 1. (i) There is a strong correlation among GFPI, CCPI, and $\mathrm{CCPI}_{\mathrm{f}}$. WPI $\mathrm{f}$ and WPI (Table 5) (ii) The long term trend in CPI has followed a pattern similar to CPI $\mathrm{f}$, GFPI behaviours.

Table 5. Correlation coefficients between price indices

\begin{tabular}{|c|c|c|c|c|c|c|}
\hline & CCPI & $\mathrm{CCPI}_{\mathrm{f}}$ & GFPI & OILSPI & WPI $_{\mathrm{f}}$ & WPI \\
\hline $\mathrm{CCPI}$ & 1.000 & & & & & \\
\hline $\mathrm{CCPI}_{\mathrm{f}}$ & $0.996(0.000)$ & 1.000 & & & & \\
\hline GFPI & $0.910(0.000)$ & $0.919(0.000)$ & 1.000000 & & & \\
\hline OILSPI & $0.698(0.000)$ & $0.723(0.000)$ & $0.906(0.000)$ & 1.000000 & & \\
\hline $\mathrm{WPI}_{\mathrm{f}}$ & $0.982(0.000)$ & $0.989(0.000)$ & $0.937(0.000)$ & $0.766(0.000)$ & 1.000 & \\
\hline WPI & $0.990(0.000)$ & $0.991(0.000)$ & $0.944(0.000)$ & $0.764(0.000)$ & $0.995(0.000)$ & 1.000 \\
\hline
\end{tabular}

*P values are in parenthesis

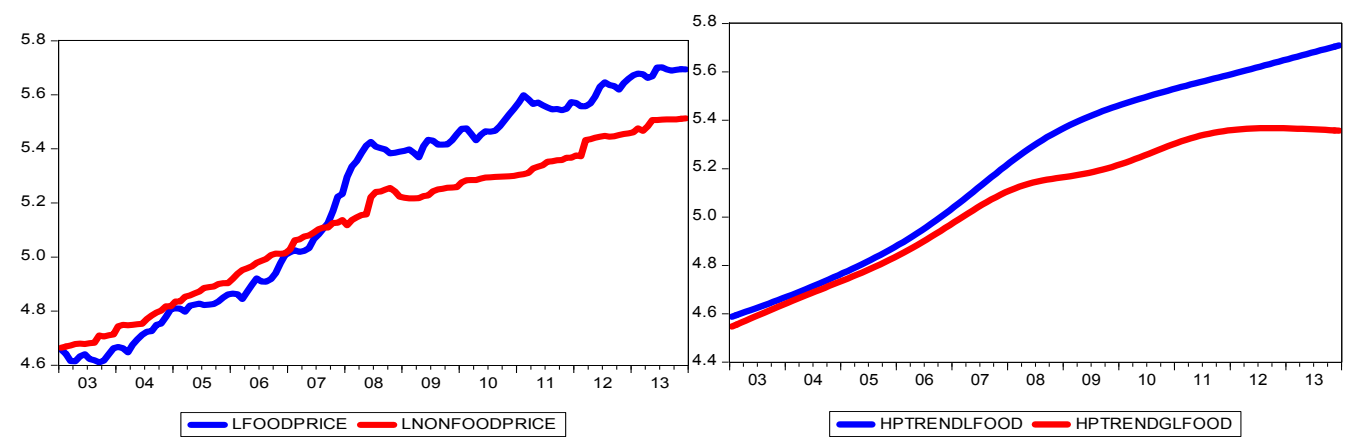

(a) (b)

Figure 2. Divergence of food prices in Sri Lanka, 2003-2013 
This evidence shows that food prices may be an important source of inflationary pressures in Sri Lanka. Figure 2 (a) shows the divergence between CPI for food items and CPI for nonfood items has increased since 2007 while figure 2(b) indicates global food price and local food price are with upward trend and co-moved. The gap between these two price trends was increasing along with time. Domestic and international food price inflation rates have been positively and significantly correlated.

\subsection{Empirical Behaviour of Autocorrelation Function Structure of Food Price}

The lagged scater plot shows the simplest graphical summary of autocorrelation in a time series. The lagged scatter plot with confidence ellipse, nearest neighbour fit show that food price series highly depend on its lag value. Time plots in food inflation series shows that variance in the food inflation changes over time. The Figure 3 exhibits three lagged scatter plots with 95 percent confidence ellipse (i) scatter plots of log of CPI for food price $\left(\mathrm{LCPI}_{\mathrm{f}}\right)$ of month $t$ against $\log$ of CPI for food price of month $t-1\left(\mathrm{LCPI}_{\mathrm{f}, \mathrm{t}-1}\right)$ and (ii) scatter plots of food inflation $^{1}\left(\mathrm{INF}_{\mathrm{f}}\right)$ of moth $\mathrm{t}$ against food inflation ${ }^{1}\left(\mathrm{INF}_{\mathrm{ft}-1}\right)$ of month $t$-1. (iii) Food inflation ${ }^{2}$ of month $t$ against food inflation ${ }^{2}$ of month $t-1$. (i) and (ii) the scatters are dense around the centre line which suggests that food inflation has the properties associated with random walk. This indicates that the value at time $t$ depends on the value at $t-1$.
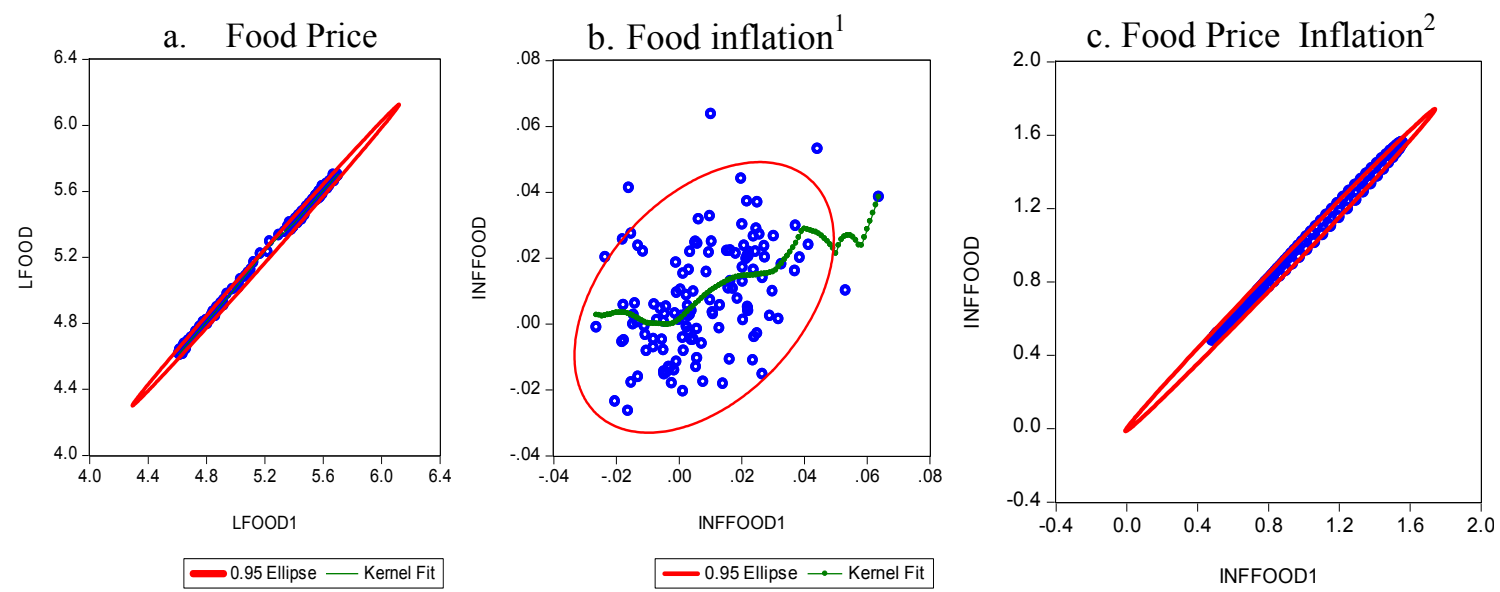

Figure 3. Autocorrelation nature of food price, food price inflation, Sri Lanka 2003-2013

(Note: 1: food inflation is calculated from log food price index. 2: food inflation is calculated from HP filtered $\log$ food price trend.). LFOOD1, INFFOOD1 refers one lag of food price index, food price inflation with lag one respectively.

These scatter plot with confidence ellipse shows the dependence nature of the food price dynamics in level as well as in rate of changes. All scatter plots show these variables are highly positively auto-correlated. Hence, food price or food price inflation is highly persistent.

The autocorrelation function (ACF) can be used as a preliminary diagnostic tool of long memory. ACF represents the degree of persistence over respective lags of a variable. A slow decay of the ACF is an indicator of long memory. Sample ACFs for CPI for food and CCPI for all items decay slowly to zero at a polynomial rate as the lag increases. This type of process is referred to as long-memory time series. The autocorrelation coefficient of $\mathrm{CCPI}_{\mathrm{f}}$ starts at a very high value (0.977) close to 1 and declines very slowly toward zero as the lag lengthens (Figure 4). Autocorrelations for the first 36 lags range between approximately 0.973 and 0.02 , providing strong evidence of the presence of serial correlation. Results indicate that $\mathrm{CCPI}_{\mathrm{f}}$ series has a very long memory and is largely persistent with lagged coefficients that are clearly statistically significant. The impact of a shock $\mathcal{E}_{t}$ on $\mathrm{CCPI}_{\mathrm{f}}$ does not diminish over time. Therefore, the shocks on food price are persistent.

Sample autocorrelations of inflation are generally very small and statistically insignificant at a 5 percent level. Whereas the sample autocorrelations for food price inflation, the absolute and squared food price inflation are significantly different from zero even for large lags. Figure 5 shows the ACF of absolute price changes decays slowly as a function of time lag according to a power law. This behaviour suggests that there is some kind of long-range dependence in the food inflation series. This series has a very long memory. It shows the serial dependence for the absolute and squared price changes are positive, significant and decays very slowly as lag 
length increases. This indicating food price inflation series values are dependent to own past distant values. In addition, the ACF for absolute food inflation series is higher than the ACF for squared food inflation series.
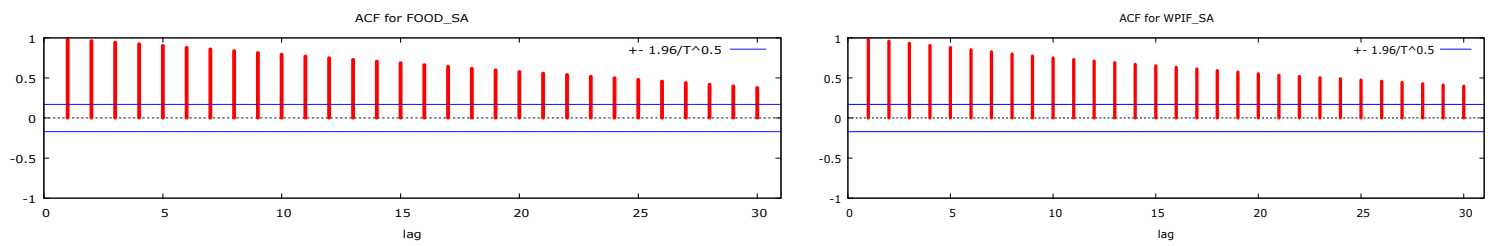

PACF for FOOD_SA


Figure 4. ACF of Food Price Series, Sri Lanka

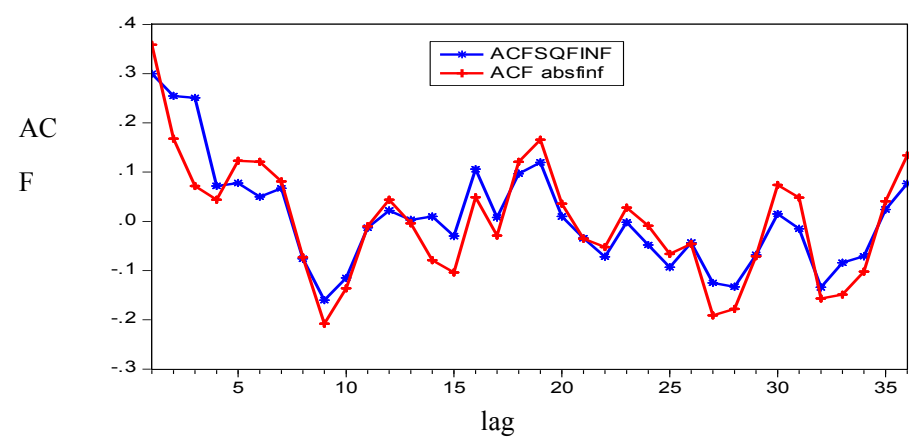

Figure 5. ACF of absolute and squared food price inflation

These sample ACFs show that the impact of a shock $\varepsilon_{t}$ on food inflation does not diminish over time. The past shocks continue to play a significant role in determining the future food price path. Therefore, the shocks on food price are persistent.

The $p$ value for (Ljung-Box test statistic) the joint significance of the correlation coefficients, indicates that they are significantly different from zero even for large lags. This implies the autocorrelation exist for longer time. If data are I(d), sample ACF are consistent with the following convergence rates (Brockwell \& Davis (1995) and Baillie (1996):

Table 6. Type of Convergence of ACF

\begin{tabular}{cc}
\hline$D$ & Rate of Convergence of ACF \\
\hline$-0.5<d<0.25$ & $T^{0.5}$ \\
$d=0.25$ & $(\mathrm{~T} / \ln (\mathrm{T}))^{0.5}$ \\
$0.25<d<0.25$ & $T^{0.5-d}$ \\
\hline
\end{tabular}

In this respect, identification of long memory by use of sample ACF is well bounded.

\subsection{Visual Inspection of Spectral Density Function}

In addition, spectral methods are useful to uncover key characteristics of economic time series for model building. Granger (1966) describes how the spectral shape of an economic variable concentrates spectral mass at low frequencies, declining smoothly as frequencies increases. The series $\mathrm{y}_{\mathrm{t}}$ displays long memory if its spectral density, $f_{Y}$ increases without limit as angular frequency tends to zero. $\lim _{\lambda \rightarrow 0} f_{Y}(\lambda)=\infty$. The periodogram measures the amplitude of a time series for all possible frequencies and wavelengths. In a spectral graph, periodogram, density is rapidly declining when frequencies increases for white noise variable. Long run dependence can be seen by the relatively flat spectral density over higher frequencies. 



Figure 6. Spectral density function for food price series $\left(\mathrm{CPI}_{\mathrm{f}}, \mathrm{WPI}_{\mathrm{f}}\right)$


Figure 7. Spectral Density Functions for Food Price Inflation

Figure 6 and Figure 7 both point to the possibility that food price series, food price inflation series exhibit long memory.

4.4 Unit Root Test Results

Table 7. Unit Root Tests (KPSS) for Inflation Series from HP filtered Prices

\begin{tabular}{lc}
\hline Variables & KPSS Test Statistic (LM) \\
\hline CPI Food Price -inf $\left(\boldsymbol{\pi}_{d, t}^{f^{*}}\right)$ & 0.6235 \\
CPI Food price -inf First difference $\left(\boldsymbol{d} \boldsymbol{\pi}_{d, t}^{f^{*}}\right)$ & 0.338 \\
Global food price-inf $\left(\boldsymbol{\pi}_{G, t}^{f^{*}}\right)$ & 0.959 \\
Global food price-inf First difference $\left(\boldsymbol{d} \boldsymbol{\pi}_{G, t}^{f^{*}}\right)$ & 0.137 \\
Non-food price - inf $\left(\boldsymbol{\pi}_{d, t}^{N f^{*}}\right)$ & 1.046 \\
Non-food price-inf first difference $\left(\boldsymbol{d} \boldsymbol{\pi}_{d, t}^{N f^{*}}\right)$ & 0.166 \\
Whole sale food price-inf $\left(\boldsymbol{\pi}_{W P I, t}^{f^{*}}\right)$ & 0.639 \\
Whole sale food price inf-first difference $\left(\boldsymbol{d} \boldsymbol{\pi}_{W P I, t}^{f^{*}}\right)$ & 0.255 \\
Whole sale price - inf $\left(\boldsymbol{\pi}_{W P I, t}^{*}\right)$ & 0.932 \\
Whole sale price inf-first difference $\left(\boldsymbol{d} \boldsymbol{\pi}_{W P I, t}^{*}\right)$ & 0.203 \\
CPI-inf $\left(\boldsymbol{\pi}_{C P I, t}^{*}\right)$ & 0.852 \\
CPI-first difference $\left(\boldsymbol{d} \boldsymbol{\pi}_{C P I, t}^{*}\right)$ & 0.246 \\
\hline (Note:* indicates inflation is calculated from HP filtered trend data), critical value= 0.463
\end{tabular}


The results of standard unit root tests ADF, PP, and KPSS show the food price series are non-stationary, I(1) and Food inflation series is stationary, $\mathrm{I}(0)$. All these tests only count the integer order of integration of the series. I(1) or I(0). (Results can be obtained from first author). It has not identified the fractional integration. It is interesting to note that food inflation calculated from the HP filtered food price trend is non-stationary. KPSS test results show that food price inflation derived from HP filtered trend food price is non-stationary (Table 7). This indicates that there is some contradictions from standard unit root tests ADF and PP test.

This limitation indicates that there is a need for a more general class of ARFIMA models to investigate the stochastic properties of food price inflation series.

\subsection{The Rescaled Range Statistic (R/S) Plot and Hurst Estimator (H)}

The results of the rescaled range analysis (Table 8 ) show that all $H$ estimates are greater than 0.5 . It implies that all price changes, all inflation series are persistent.

Table 8. Hurst Estimates

\begin{tabular}{lll}
\hline Price Series & $H^{I}$ & $H^{2}$ \\
\hline CPI food inflation & 0.7427 & $\approx 1$ \\
CPI headline inflation & 0.8159 & $\approx 1$ \\
WPI food inflation & 0.6246 & 0.987 \\
WPI inflation & 0.6337 & $\approx 1$ \\
Global food inflation & 0.6364 & 0.959 \\
Non-food inflation & 0.7174 & $\approx 1$ \\
\hline
\end{tabular}

Note 1: denotes inflation with cycle component, 2: inflation without cycle component (using Hodrick-Prescott filter), $0<H<0.5$ :Anti-persistent, $H=0.5$ : Random walk, $0.5<H<1$ : Persistence

Hurst exponent (HE) can be obtained by plotting graph the range of the data on $\mathrm{X}$ axis (as measured by the highest and lowest values in the time period), and the standard deviation of the data in $\mathrm{Y}$ axis. A derivative of this statistical graph (slope of the regression) is known as a HE. The Figure 8 shows the relationship between logarithm of data length versus logarithm of rescale range $(R / S)$ for cases. It shows approximately a positive straight line relationship between these variables, higher data length the higher the average computed rescale range value. This suggests the spectral density s(f) scales with frequency f as a power law $S(f) \sim f^{-H}$. H is the slope of the fitted trend line that shows the relationship between $\log (R / S)$ and $\log$ of time. For food inflation, the values of $\mathrm{H}$ statistic in Table $8(0.5<H<1)$ provide strong evidence for long memory in all inflation series.

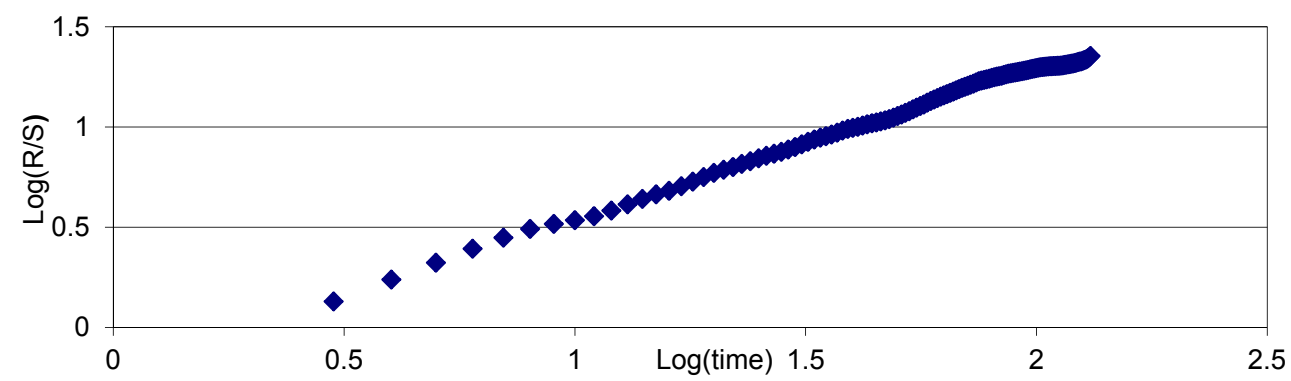

Figure 8 . The rescaled range statistic plot for food price inflation

\subsection{Semi-Parametric GPH Estimate “ $\hat{d}$ ”}

We compute the fractional integration parameter using algorithms built in GRETL. There are two methods we use here to estimate fractional parameter " $d$ " (i) proposed by Geweke and Porter-Hudak method ( $d_{\mathrm{GPH}}$ ) (ii) Local Whittle estimator $\left(d_{\mathrm{LW}}\right)$ : These both methods estimate " $d$ " using a frequency domain maximum likelihood estimation to check long memory properties of food price series. The results are given in Table 9.

Periodogram graphs (Figure 6 and 7) and GPH " $d$ " estimates (Table 9) show the food price series is fractionally integrated and has long memory. Evidence of long memory is found in all of the price series studied, as the estimated " $d$ " values close to one $(\sim 1)$ for food price series and estimated values of GPH $d$ range from 0.27 to 0.43 except for nonfood price inflation which has $d=0.712$ which is not statistically significant. GPH estimates 
for food price inflation series are statistically significant at the 5 percent level and indicate all variables are persistent. Hence, food price inflation series are not transitory and have long memory.

Table 9. Geweke and Porter-Hudak Estimates and Local Whittle Estimates

a) Food Prices

b) Food Price Inflation

\begin{tabular}{llllll}
\hline Price & $\mathrm{GPH} \hat{d}^{\prime \prime}$ & $\mathrm{LWE} \hat{d}$ & $\mathrm{Inflation}$ & $\mathrm{GPH}{ }^{\prime \prime}$ & $\mathrm{LWE} \hat{d}$ \\
\hline $\mathrm{CPI}$ & $1.04(0.000)$ & $1,01(0.000)$ & $\mathrm{INF}_{\mathrm{H}}$ & $0.43(0.00 .3)$ & $0.287(0.000)$ \\
$\mathrm{CPI}_{\mathrm{F}}$ & $1.05(0.000)$ & $1.04(0.000)$ & $\mathrm{INF}_{\mathrm{F}}$ & $0.43(0.018)$ & $1.06(0.000)$ \\
$\mathrm{GFPI}$ & $1.19(0.000)$ & $1.14(0.000)$ & $\mathrm{INF}_{\mathrm{GFPI}}$ & $0.41(0.004)$ & $0.54(0.000)$ \\
$\mathrm{WPI}_{\mathrm{F}}$ & $1,04(0.000)$ & $1.05(0.000)$ & $\mathrm{INF}_{\mathrm{WPIF}}$ & $0.28(0.073)$ & $0.29(0.000)$ \\
$\mathrm{WPI}$ & $1,03(0.000)$ & $1.04(0.000)$ & $\mathrm{INF}_{\mathrm{WP}}$ & $0.44(0.003)$ & $0.49(0.000)$ \\
$\mathrm{CPI}_{\mathrm{NF}}$ & $1.02(0.000)$ & $0.98(0.000)$ & $\mathrm{INF}_{\mathrm{NF}}$ & $0.117(0.452)$ & $0.12(0.169)$ \\
\hline
\end{tabular}

\subsection{ARFIMA Model}

a) Long Memory Estimates (d) for Mean of Food Price Series

ARFIMA model is used to estimate long memory parameter using maximum likelihood estimation method. The selected ARFIMA model, for all price series and inflation series, is ARFIMA $(1, d, 0)$. Table 10 shows Long memory parameter estimates for the selected ARFIMA models.

Table 10. Results from ARFIMA (1,d,0) Models for Price series

\begin{tabular}{cccccc}
\hline ITEMS & Constant & AR & $D$ & LL & Wald-Chi $^{2}$ \\
\hline CCPI & Ns & $0.997(0.000)$ & $0.355(0.000)$ & -257.049 & 161662.03 \\
CCPI $_{\mathrm{f}}$ & $\mathrm{Ns}$ & $0.991(0.000)$ & $0.379(0.000)$ & -334.76 & 24646.82 \\
CCPI $_{\mathrm{Nf}}$ & $\mathrm{Ns}$ & $0.999(0.000)$ & $0.196(0.000)$ & -285.41 & 1429024.57 \\
GFPI & $\mathrm{Ns}$ & $0.929(0.000)$ & $0.487(0.000)$ & -384.67 & 3060.56 \\
WPI & $\mathrm{Ns}$ & $0.996(0.000)$ & $0.239(0.001)$ & -768.45 & 79086.17 \\
WPI $_{\mathrm{F}}$ & $\mathrm{Ns}$ & $0.992(0.000)$ & $0.281(0.002)$ & -284.96 & 24249.05 \\
\hline
\end{tabular}

Note: This table shows the results of selected ARFIMA( $(1, \mathrm{~d}, 0)$ models. AR indicates the autoregressive parameter; LL indicates the log likelihood, $d$ indicates the long memory, parameter, $p$ values are in parentheses; ns denotes not significance, $d=$ fractional difference parameter

In all cases, estimates of long memory parameter $d$ which are highly significant at the 5 percent level and lie in the interval $(0,0.5)$, implying that the series are stationary but exhibit long memory. Global food price has relatively higher long memory. Positive values of the fractional differencing parameter indicate long memory. Long memory indicates that shocks to these prices may persist over a long period of time. These evidences imply predictability of future food prices based on historical prices. The significant $d$ parameter estimates for each series ranges from 0.196 to 0.489 . The ARFIMA model estimation results indicate that food inflation is persistent and having long memory behavior. Non-stationary of the series does not necessarily imply long run divergence of the series from its mean value. It is well known that a series with $0.5<d<1$, is mean-reverting even though it is non-stationary.

b. Food Inflation Series and Persistence

Table 11. ARFIMA (0,d,0)-Long Memory Parameter Estimates $(\hat{d})$ of Inflation series

\begin{tabular}{llll}
\hline ITEMS & $\hat{d}$ & LL & Wald-Chi $^{2}$ \\
\hline INFF & $0.203(0.019)$ & 362.17 & 39.19 \\
INFH & $0.326(0.000)$ & 439.77 & 33.95 \\
INFNF & $0.292(0.000)$ & 622.18 & 34.52 \\
INFWFP & $0.230(0.002)$ & 272.33 & 9.15 \\
INFWP & $0.189(0.002)$ & 298.68 & 9.97 \\
INFGF & $0.438(0.000)$ & 297.49 & 49.81 \\
\hline
\end{tabular}

$\left(P\right.$ values are in parenthesis $\left.\mathrm{H}_{0}: d=0\right)$ 
Long memory parameter is estimated for all inflation series. Long memory parameter estimates in conditional mean are (Table 11): $d=0.326(0.00)$ for headline inflation, $d=0.203(0.00)$ for food inflation, $d=0.292$ for nonfood inflation. These results indicate that food inflation series is said to be long memory, stationary, positive autocorrelations that decay hyperbolically. The evidence of long memory parameter in food inflation indicates the predictability of food inflation behaviour.

All the long memory parameters are statistically significant at the 5 percent level, and the estimates indicate a high degree of dependence in the series. Further, in ARFIMA framework, we experimented inflation series after filtering the series by the HP method. Long memory parameter is estimated for the filtered series now. The results are given in Table 12.

Table 12. ARFIMA-Long memory parameter estimates of inflation series

\begin{tabular}{lccc}
\hline ITEMS & $d^{*}$ & LL & Wald-Chi $^{2}$ \\
\hline INFCFPI & $0.4992(0.000)$ & 139.29 & 227164.13 \\
INFCPI & $0.4991(0.000)$ & 205.64 & 608241.55 \\
INFCPINF & $0.4997(0.000)$ & 256.06 & 1674967.00 \\
INFWFPI & $0.4992(0.000)$ & 131.85 & 214012.35 \\
INFWPI & $0.4994(0.000)$ & 162.39 & 383659.78 \\
INFGF & $0.4988(0.000)$ & 112.11 & 101885.49 \\
\hline
\end{tabular}

Note: * Estimated from the filtered the series by the HP method

The evidence from Tables 11 and 12 indicate that food inflation possess long memory. In general, price series may have long memory not only in first moment of the series but also in second moments of the series. Now, we will investigate the characteristics of the second moment of the series (volatility). The following section describes the persistence of food inflation volatility in Sri Lanka.

c. Long Memory in Volatility of Food Inflation

The volatility series (conditional variance) for food price inflation is generated using GARCH model. Results show that variance of the food inflation series depends on the past. The coefficients GARCH terms in the conditional variance equation are highly significant. The GARCH effect is 0.87 which implies that shocks to the conditional variance will be highly persistent (Brooks, 2005, p 465). This indicates that shocks push variance away from its long-run average (Christoffersen, 2012). For each volatility series, Hurst exponent and ARFIMA " $d$ " were estimated. The results are given in Table 13 below.

Table 13. Long memory parameter estimates

(a) Hurst Exponent

(b) ARFIMA

\begin{tabular}{lclccc}
\hline Volatility Series & $\hat{H}$ & Items & $\hat{d}$ & LL & Wald-Chi $^{2}$ \\
\hline Volatility of CPI food inflation & 0.965 & Vol_INF $_{\mathrm{F}}$ & $0.494(0.000)$ & 1183.71 & 5842.78 \\
Volatility of CPI headline inflation & 9.582 & Vol_INF $_{\mathrm{H}}$ & $0.495(0.000)$ & 1367.46 & 14366.22 \\
Volatility of WPI food inflation & 0.819 & Vol_INF$_{\mathrm{WPF}}$ & $0.274(0.000)$ & 800.97 & 79711.16 \\
Volatility of WPI inflation & 0.917 & Vol_INF $_{\mathrm{WP}}$ & $0.002(0.000)$ & 1094.09 & 382912.28 \\
Volatility of Global food inflation & 0.916 & Vol_INF $_{\mathrm{GFPI}}$ & $0.028(0.722)$ & 1052.69 & 16451.81 \\
Volatility of CPI non-food inflation & 0.863 & Vol_INF $_{\mathrm{NF}}$ & $0.448(.000)$ & 917.16 & 737.74 \\
\hline & & \multicolumn{3}{c}{ (probability value in parenthesis) }
\end{tabular}

According to the Table 13, Hurst exponent and ARFIMA " $d$ " estimates show that all volatility series of inflation are highly persistent (as $H>0.5,0<d<0.5$ ). Volatility of food price inflation is also indicates that food inflation is long memory not in transitory nature.

The ACF of volatility series given in Figure 9 also proves that food inflation is a long memory processes as ACF of these series decay hyperbolically, and the evidence of long memory in volatility reveals uncertainty (risk) in the behaviour of food prices. 


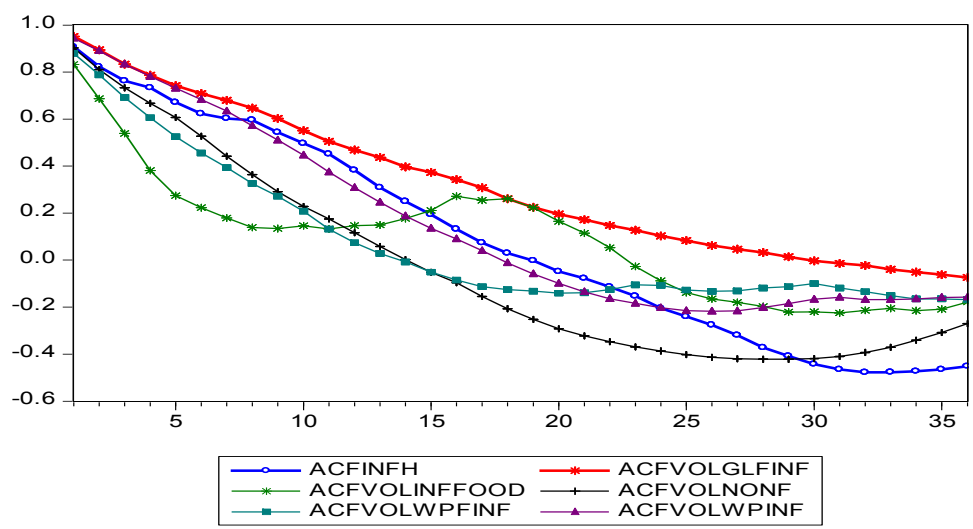

Figure 9. ACF of Volatility Series

Food price inflation cycles were extracted by filtering the series with the HP method. GARCH model was fitted for this cycle and estimated ARCH and GARCH coefficients. The sum of the coefficients on the lagged squared error and lagged conditional variance is very close to unity. This implies that shocks to the conditional variance will be highly persistent. This will lead to future forecasts of the variance to be high for a extended period. These estimated results also suggest that food inflation series exhibits evidence of long memory.

Thus, the assumption that food (and energy) prices do not contribute to underlying inflationary pressures in the economy is incorrect. A common measure of inflation is headline inflation minus food and energy (Silver, 2007). The assumption is valid when the excluded items, food and energy are volatile elements that of a temporary nature with short memory. If they are persistent nature (long memory) those elements should be added in the core inflation measure. As food inflation play important role in inflation dynamics and food price inflation is long memory series, it is not appropriate to remove from inflation calculation.

\section{Conclusions and Recommendations}

In this study, we estimated order of integration of various food price and food price inflation series in Sri Lanka using fractional integration methods. A battery of nonparametric, semi-parametric and parametric tests was used to investigate long memory of food price series. All these tests show that food price series have long memory and they are fractionally integrated. Results suggest that food price series are not transitory in nature and have significant permanent components which imply strong evidence of persistence in food inflation in Sri Lanka. This result contradicts with other studies results for food prices as $I(1)$ or $I(0)$ for food price inflation. Policy makers may include food prices in the computation of any measure long run inflation where this inclusion could provide a clear picture of underlying inflation trends. The empirical results of this study have important policy implications for food, trade and monetary policy makers. Results suggest that neglecting food prices may render the core inflation a biased measure of long run inflation and the appropriate policy may focus is on headline inflation.

\section{Acknowledgements}

First author wishes to express his gratitude to Prof. dr. Jan G. De Gooijer, Prof. dr. H.P Boswijk, Prof. dr. J.F. Kiviet, University of Amsterdam, The Netherlands, and thank Prof Sumanasri Liyanage, MS. Achinthya Tharangani Koswaththa, University of Peradeniya, Sri Lanka for correcting the errors and helpful comments.

\section{References}

Al-Eyd, A., Amaglobeli, D., Shukurov, B., \& Sumlinski, M. (2012). Global Food Price Inflation and Policy Responses in Central Asia. IMF WP/12/86 International Monetary Fund, Washington DC. Retrieved from http://papers.ssrn.com/sol3/papers.cfm?abstract_id=2050262

Backus, D., \& Zin, S. E. (1993). Long-memory inflation uncertainty: Evidence from the term structure of interest rates. Journal of Money, Credit and Banking, 25(3), 681-700. http://dx.doi.org/10.2307/2077735

Baillie, R. T. (1996). Long memory processes and fractional integration in econometrics. Journal of Econometrics, 73(1), 5-59. http://dx.doi.org/10.1016/0304-4076(95)01732-1

Baillie, R. T., \& Myers, R. J. (1991). Bivariate GARCH estimation of the optimal commodity futures hedge. Journal of Applied Econometrics, 6(2), 109-124. http://dx.doi.org/10.1002/jae.3950060202 
Baillie, R. T., Bollerslev, T., and Mikkelsen, H. O. (1996). Fractionally integrated generalized autoregressive conditional heteroskedasticity. Journal of Econometrics, 74(1), 3-30. http://dx.doi.org/10.1016/S03044076(95)01749-6

Ball, L., Cecchetti, S. G., \& Gordon, R. J. (1990). Inflation and uncertainty at short and long horizons. Brookings Papers on Economic Activity, 215-254. http://dx.doi.org/10.2307/2534528

Barkoulas, J., Labys, W. C., \& Onochie, J. (1997). Fractional dynamics in international commodity prices. Journal of Futures Markets, 17(2), 161-189. http://dx.doi.org/10.1002/(SICI)1096-9934(199704)17:2< $161::$ AID-FUT2 $>3.0 . \mathrm{CO} ; 2-\mathrm{H}$

Barsky, R. B. (1987). The Fisher hypothesis and the forecastability and persistence of inflation. Journal of Monetary Economics, 19(1), 3-24. http://dx.doi.org/10.1016/0304-3932(87)90026-2

Baum, C. F., Barkoulas, J. T., \& Caglayan, M. (1999). Long memory or structural breaks: Can either explain nonstationary real exchange rates under the current float?. Journal of International Financial Markets, Institutions and Money, 9(4), 359-376. http://dx.doi.org/10.1016/S1042-4431(99)00018-9

Beran, J. (1994). Statistics for long-memory processes (Vol. 61). CRC Press.

Bhatt, V., \& Kishor, N. K. (2014). Are All Movements in Food and Energy Prices Transitory? Evidence from India. conference on Indian macroeconomic policy, Indian Statistical Institute, Delhi Centre. http://dx.doi.org/10.1016/j.jpolmod.2015.01.005

Bilke, L., \& Stracca, L. (2007). A persistence-weighted measure of core inflation in the Euro area. Economic Modelling, 24(6), 1032-1047. http://dx.doi.org/10.1016/j.econmod.2007.04.001

Bos, C. S., Franses, P. H., \& Ooms, M. (1999). Long memory and level shifts: Re-analyzing inflation rates. Empirical Economics, 24(3), 427-449. http://dx.doi.org/10.1007/s001810050065

Brooks, C. (2005). Introductory econometrics for finance. Cambridge university press.

Cecchetti, S. (1997) Measuring Short-Run Inflation for Central Bankers. Federal Reserve Bank, of St. Louis Review, 79, 143-155. http://dx.doi.org/10.3386/w5786

Cecchetti, S. (2006). Core inflation is an unreliable guide. Financial Times, 9(12), 2006.

Cecchetti, S. G., Hooper, P., Kasman, B. C., Schoenholtz, K. L., \& Watson, M. W. (2007, March). Understanding the evolving inflation process. In US Monetary Policy Forum (Vol. 8). Retrieved from https://www.princeton.edu/ mwatson/papers/USMPF_Report_July_2007 .pdf

Central Bank of Sri Lanka. (2013). Annual Report.

Christoffersen, P. F. (2012). Elements of financial risk management. Academic Press.

Cooke, B. (2009). Recent food prices movements: A time series analysis (Vol. 942). Intl Food Policy Res Inst. Retrieved from http://citeseerx.ist.psu.edu/viewdoc/download?doi=10.1.1.227.1700\&rep=rep1\&type=pdf

Cutler, J. (2001). Core Inflation in the UK (No. 3). External MPC Unit Discussion Paper, Bank of England. Retrieved from http://hdl.handle.net/10419/84678

Deaton, A. (1999). Commodity prices and growth in Africa. The Journal of Economic Perspectives, 23-40. http://dx.doi.org/10.1257/jep.13.3.23

DeBoef, S., \& Granato, J. (1997). Near-integrated data and the analysis of political relationships. American Journal of Political Science, 619-640. http://dx.doi.org/10.2307/2111780

Delgado, M. A., \& Robinson, P. M. (1994). Optimal spectral bandwidth for long memory. Statistica Sinica 6, 97-112. Retrieved from http://hdl.handle.net/10016/2425

Department of Census and Statistics. (2012). Household Income and Expenditure Survey. Sri Lanka.

Diebold, F. X., \& Nerlove, M. (1989). The dynamics of exchange rate volatility: a multivariate latent factor ARCH model. Journal of Applied econometrics, 4(1), 1-21. http://dx.doi.org/10.1002/jae.3950040102

Geweke, J., \& Porter - Hudak, S. (1983). The estimation and application of long memory time series models. Journal of time series analysis, 4(4), 221-238. http://dx.doi.org/10.1111/j.1467-9892.1983.tb00371.x

Gilbert, C. L. (2010). How to understand high food prices. Journal of Agricultural Economics, 61(2), 398-425. http://dx.doi.org/10.1111/j.1477-9552.2010.00248.x

Gilbert, C. L., \& Morgan, C. W. (2010). Food price volatility. Philosophical Transactions of the Royal Society B: 
Biological Sciences, 365(1554), 3023-3034. http://dx.doi.org/10.1098/rstb.2010.0139

Granger, C. W. (1966). The typical spectral shape of an economic variable. Econometrica: Journal of the Econometric Society, 150-161. http://dx.doi.org/10.2307/1909859

Granger, C. W., \& Joyeux, R. (1980). An introduction to long - memory time series models and fractional differencing. Journal of time series analysis, 1(1), 15-29. http://dx.doi.org/10.1111/j.1467-9892.1980. tb00297.x

Hassler, U. (1993). Regression of spectral estimators with fractionally integrated time series. Journal of Time Series Analysis, 14(4), 369-380. http://dx.doi.org/10.1111/j.1467-9892.1993.tb00151.x

Hassler, U., \& Wolters, J. (1995). Long memory in inflation rates: International evidence. Journal of Business \& Economic Statistics, 13(1), 37-45. http://dx.doi.org/10.2307/1392519

Hosking, J. R. (1981). Fractional differencing. Biometrika, 68(1), 165-176. http://dx.doi.org/10.1093/biomet/ 68.1.165

Hsieh, D. A. (1988). The statistical properties of daily foreign exchange rates: 1974-1983. Journal of international economics, 24(1), 129-145. http://dx.doi.org/10.1016/0022-1996(88)90025-6

Hurst, H. E. (1951). Long-term storage capacity of reservoirs. Trans. Amer. Soc. Civil Eng., 116, 770-808. http://www.citeulike.org/group/2384/article/7655765

Jin, H. J., \& Frechette, D. L. (2004). Fractional integration in agricultural futures price volatilities. American Journal of Agricultural Economics, 86(2), 432-443. http://dx.doi.org/10.1111/j.0092-5853.2004.00589.x

Kallon, K. M. (1994). An econometric analysis of inflation in Sierra Leone. Journal of African Economies, 3(2), 199-230.

Klein, B. (1976, December). The social costs of the recent inflation: The mirage of steady "anticipated" inflation. In Carnegie-Rochester Conference Series on Public Policy, 3, 185-212. North-Holland. Retrieved from http://www.sciencedirect.com/science/article/pii/0167223176900452

Kohzadi, N., \& Boyd, M. S. (1995). Testing for chaos and nonlinear dynamics in cattle prices. Canadian Journal of Agricultural Economics/Revue canadienne d'agroeconomie, 43(3), 475-484. http://dx.doi.org/10.1111/j. 1744-7976.1995.tb00136.x

Kovács, S., Huzsvai, L., \& Balogh, P. (2013). Investigating the long memory property of the Hungarian market pig prices by using detrended fluctuation analysis. Journal of Agricultural Informatics, 4(2), 1-9.

Loening, J. L., Durevall, D., \& Ayalew Birru, Y. (2009). Inflation dynamics and food prices in an agricultural economy: The case of Ethiopia. Rapport nr.: Working Papers in Economics 347. http://dx.doi.org/10.1596/1813-9450-4969

Mandelbrot, B. B. (1975). Limit theorems on the self-normalized range for weakly and strongly dependent processes. Zeitschrift für Wahrscheinlichkeitstheorie und verwandte Gebiete, 31(4), 271-285. http://dx.doi.org/10.1007/BF00532867

Mishra, P., \& Roy, D. (2012). Explaining Inflation in India: The Role of Food Prices. Shekhar Shah Barry Bosworth Arvind Panagariya, 139. Retrieved from http://demo.ncaer.org/downloads/Journals/IPF_2011_ 12_IPF-Vol_8.pdf\#page $=159$

Moriyama, K., \& Naseer, A. (2009). Forecasting inflation in Sudan. WP/09/132, International Monetary Fund. http://dx.doi.org/10.5089/9781451872798.001

Rangasamy, L. (2009). Inflation persistence and core inflation: The case of South Africa. South African Journal of Economics, 77(3), 430-444. http://dx.doi.org/10.1111/j.1813-6982.2009.01222.x

Silver, M. (2007). Core inflation: Measurement and statistical issues in choosing among alternative measures. IMF Staff Papers, 163-190. http://dx.doi.org/10.1057/palgrave.imfsp.9450006

Stigler, M., \& Prakash, A. (2011). Commodity prices: theoretical and empirical properties. Safeguarding food security in volatile global markets, 27-44. Retrieved from http://www.fao.org.webtranslate-widget. systransoft.com/docrep/013/i2107e/i2107e17.pd

Vega, J. L., \& Wynne, M. A. (2003). A first assessment of some measures of core inflation for the euro area. German Economic Review, 4(3), 269-306. http://dx.doi.org/10.1111/1468-0475.00082

Walsh, J. P. (2011). Reconsidering the role of food prices in inflation. WP/11/71, International Monetary Fund. 
http://dx.doi.org/10.5089/9781455227082.001

Wang, D., \& Tomek, W. G. (2007). Commodity prices and unit root tests. American Journal of Agricultural Economics, 89(4), 873-889. http://dx.doi.org/ 10.1111/j.1467-8276.2007.01031.x

$\mathrm{Wu}, \mathrm{Y}$. (2004). Understanding international food consumption patterns. University of Western Australia, Business School, Economics.

\section{Copyrights}

Copyright for this article is retained by the author(s), with first publication rights granted to the journal.

This is an open-access article distributed under the terms and conditions of the Creative Commons Attribution license (http://creativecommons.org/licenses/by/3.0/). 